Check for updates

Cite this: RSC Adv., 2019, 9, 7955

Received 10th January 2019

Accepted 25th February 2019

DOI: $10.1039 / c 9 r a 00210 c$

rsc.li/rsc-advances

\title{
A lysosome-targetable fluorescent probe for the simultaneous sensing of Cys/Hcy and GSH from different emission channels $\dagger$
}

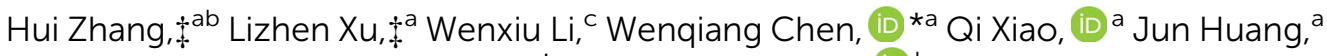 \\ Chusheng Huang, ${ }^{a}$ Jiarong Sheng ${ }^{\star a}$ and Xiangzhi Song (DD ${ }^{b}$
}

\begin{abstract}
A lysosome-specific fluorescent probe, Lyso-AC, for biothiols was developed by incorporation of a 4nitrophenol moiety into a coumarin dye. The Cys/Hcy-triggered substitution-rearrangement cascade, and GSH-induced substitution reaction lead to the corresponding blue emissive amino-coumarin and yellow emissive thiol-coumarin, thereby enabling Cys/Hcy and GSH detection from distinct emissions. Moreover, this probe displayed an excellent lysosome targeting property with a 0.92 Pearson's colocalization coefficient by using Neutral Red as a reference. Significantly, biological experiments indicated Lyso-AC has the potential to monitor lysosome Cys/Hcy and GSH simultaneously in living HeLa cells from distinct emissions.
\end{abstract}

\section{Introduction}

Given that intracellular low-molecular-weight thiols (such as cysteine (Cys), homocysteine (Hcy) and glutathione (GSH)), are involved in vital pathways in human physiology, ${ }^{1,2}$ disentangling the chemical biology of these species has become a current intense interest. Biothiols play central roles in maintaining cellular redox homeostasis or combating oxidative stress and the abnormal levels of these species are closely related to critical illnesses, such as AD, psoriasis, AIDS, liver damage, cardiovascular diseases, and even cancer..$^{3-5} \mathrm{As}$ a result, precise determinations of biothiols in biological samples are meaningful in the clinical diagnosis of many diseases.

Fluorescence sensing is a powerful technique that has been extensively used to detect or visualize a wide variety of bioactive molecules by virtue of its high sensitivity and non-invasive operation as well as excellent spatiotemporal resolution..$^{6-8}$ In recent years, a large numbers of fluorescent probe for biothiols have been developed by taking advantage of various mechanisms. ${ }^{9-17}$ However, due to the intrinsic similarities exist among these species, fluorescent probes that could distinguish

${ }^{a}$ College of Chemistry and Materials Science, Guangxi Key Laboratry of Natural Polymer Chemistry and Physics, Nanning Normal University, Nanning 530001, P. R. China. E-mail: chenwq@csu.edu.cn; Fax: +86 771 3908065; Tel: +86 7713908065 ${ }^{b}$ College of Chemistry \& Chemical Engineering, Central South University, Changsha, Hunan 410083, P. R. China

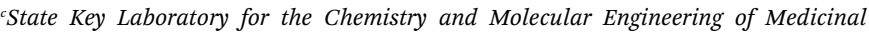
Resources of Education Ministry, Guangxi Normal University, 541004 Guilin, Guangxi, P. R. China

$\dagger$ Electronic supplementary information (ESI) available. See DOI: 10.1039/c9ra00210c

\$ These authors contributed equally. different biothiols are rare. ${ }^{18,19}$ In fact, growing evidence suggests Cys, Hcy and GSH levels in biological systems are interrelated. ${ }^{20}$ To elucidate the complicated molecular mechanism by which Cys, Hcy and GSH involved in physiological processes or diseases, fluorescent probes that can detect two or all three of them from distinct signals at the same time are urgently needed.

Contributed by Strongin and co-workers, simultaneous detection of Cys and Hcy was realized by virtue of the distinct ring-formation kinetics between Cys/Hcy and acrylates. ${ }^{21}$ From then on, some more specific probes for Cys and $\mathrm{GSH}^{22}$ or Cys/ Hcy and GSH were constructed. ${ }^{23-26}$ Recently, the differentiation of Cys, Hcy and GSH was also achieved by Yin's group through a simple molecule. ${ }^{27}$ While the above examples represent the new frontier in this field, it is noteworthy that almost all these probes only functioned at cellular level. Fluorescent probes for biothiols differentiation at subcellular level are rare, but even more valuable.

Lysosome is a membrane-bound organelle found in nearly all animal cells, it providing various hydrolases for degradation and recycling of biomacromolecules. ${ }^{28}$ Besides, lysosome also play significant roles in many cellular functions, including plasma membrane repair, cell signaling, secretion and energy metabolism. ${ }^{29}$ In lysosome, biothiols are mainly produced through the proteolysis. ${ }^{30}$ It was reported that GSH is involved in maintaining the lysosome membranes stabilization. ${ }^{31}$ Reported evidences indicating Cys and GSH are capable of promoting the intralysosomal proteolysis. For example, Cys, but not GSH, is an effective simulator of formaldehyde-treated albumin degradation in liver lysosomes; however, GSH should be a more effective stimulant of proteolysis than Cys in kidney lysosomes. ${ }^{32}$ To better understand the actual roles of each 
lysosomal thiols, the development of a lysosome-targetable fluorescent probe for sensing Cys/Hcy and GSH simultaneously is highly desirable. However, such a fluorescent probe has not been reported so far.

Herein, we have developed a lysosome targetable fluorescent probe Lyso-AC, which can simultaneously detect Cys/Hcy and GSH from blue and yellow emission channels with excellent selectivity. Significantly, simultaneously sensing of lysosomal Cys/Hcy and GSH from two distinct emissions through Lyso-AC was also realized.

\section{Experimental section}

\section{Materials and methods}

All reagents used in this work were in AR grade, which was obtained from Aladdin and J\&K without additional purification. All solvents were used in HPLC grade. The NMR spectra were tested on a BRUKER $300 \mathrm{MHz}$ NMR instrument (USA) with $0.03 \%$ TMS as an internal standard. The HRMS spectra were measured on a Waters Xevo G2 QTof MS (USA). A Shimadzu UV 2450 spectrophotometer was used for absorption spectra measuring. Fluorescence spectra were acquired on a HITACHI F-4600 spectrofluorometer. Cell images were obtained on a Zeiss LSM 710 confocal microscope (Germany).

\section{General procedure for spectral measurements}

Lyso-AC was prepared at $10^{-3} \mathrm{M}$ in DMSO as a stock solution. Aqueous solutions of cysteine (Cys), homocysteine (Hcy), glutathione (GSH), isoleucine (Ile), valine (Val), alanine (Ala), phenylalanine (Phe), serine (Ser), glutamine (Gln), histidine (His), threonine (Thr), lysine (Lys), proline (Pro), arginine (Arg), $\mathrm{KCl}, \mathrm{CaCl}_{2}, \mathrm{MgCl}_{2}, \mathrm{ZnCl}_{2}, \mathrm{NaCl}, \mathrm{Na}_{2} \mathrm{~S}, \mathrm{H}_{2} \mathrm{O}_{2}$ were newly prepared in ultrapure water. Leucine (Leu), tyrosine (Tyr), aspartic acid (Asp), glutamate (Glu) were freshly prepared in PBS buffer $(10 \mathrm{mM}, \mathrm{pH}=7.4)$. Typically, a test solution $(2.0 \mathrm{~mL})$ was prepared in a quartz cuvette by adding $0.02 \mathrm{~mL}$ of Lyso-AC ( $1 \mathrm{mM}), 0.38 \mathrm{~mL}$ of DMSO, and an appropriate volume of analyte into apposite amount of PBS buffer. The solution was well mixed and then incubated at $25^{\circ} \mathrm{C}$ for $60 \mathrm{~min}$ before measuring its optical spectra.

\section{Cell culture and fluorescence imaging procedure}

HeLa cells were obtained from the first affiliated hospital of guangxi medical university and cultured in DMEM medium (GIBCO) supplemented with $10 \%$ fbs and $100 \mu \mathrm{g} \mathrm{mL}{ }^{-1}$ penicillin. The cells were seeded in 24-well plates and allowed to adhere for $24 \mathrm{~h}$ at $37^{\circ} \mathrm{C}$ in a humidified atmosphere containing $5 \% \mathrm{CO}_{2}$. The cytotoxic effect of Lyso-AC was evaluated using classical MTT assay. $\lambda_{\mathrm{ex}}=405 \mathrm{~nm}$. Blue channel: at $450-490 \mathrm{~nm}$; yellow channel: emissions were collected at 540-580 $\mathrm{nm}$.

\section{Synthesis of compound 2}

3-Hydroxybenzoic acid (138 mg, $1 \mathrm{mmol}), N$-hydroxy succinimide (115 mg, $1 \mathrm{mmol}$ ), EDCI (192 mg, $1 \mathrm{mmol}$ ) and DMAP (5 $\mathrm{mg}$ ) were dissolved in anhydrous $\mathrm{CH}_{3} \mathrm{CN}(6 \mathrm{~mL})$. The mixture was stirred at $25^{\circ} \mathrm{C}$ for 2 hours. After removal of the solvent, the residue was used directly for next step. Mp: $184-187^{\circ} \mathrm{C} .{ }^{1} \mathrm{H}$ NMR $\left(300 \mathrm{MHz}, \mathrm{DMSO}-d_{6}\right) \delta 10.18(\mathrm{~s}, 1 \mathrm{H}), 7.52(\mathrm{t}, J=7.8 \mathrm{~Hz}, 1 \mathrm{H}), 7.44$ $(\mathrm{dd}, J=5.7,3.6 \mathrm{~Hz}, 2 \mathrm{H}), 7.21(\mathrm{~m}, 1 \mathrm{H}), 2.89(\mathrm{~s}, 4 \mathrm{H}) .{ }^{13} \mathrm{C} \mathrm{NMR}(75$ MHz, DMSO- $\left.d_{6}\right) \delta 173.24,170.80,162.22,158.40,131.22,126.03$, 123.13, 121.08, 116.41, 26.01.

\section{Synthesis of compound 3}

Compound 2 (529 mg, $2 \mathrm{mmol}$ ) and $\mathrm{N}$-(3-aminopropyl) morpholine (288 mg, $2 \mathrm{mmol}$ ) were dissolved in $10 \mathrm{~mL} \mathrm{CH}_{2} \mathrm{Cl}_{2}$. The mixture was allowed to stir for 1.5 hours at room temperature before $100 \mathrm{~mL}$ ice water was added. The resulting solution was extracted with $\mathrm{CH}_{2} \mathrm{Cl}_{2}$ twice $(2 \times 50 \mathrm{~mL})$, and the organic layer was separated and dried over $\mathrm{MgSO}_{4}$. After removal the solvent in vacuum, the resultant residue was further purified by silica gel chromatography to afford the desired product as a white solid (423 mg, 80\%). Mp: 130-133 ${ }^{\circ} \mathrm{C} .{ }^{1} \mathrm{H}$ NMR $(300 \mathrm{MHz}$, $\left.\mathrm{CDCl}_{3}\right) \delta 8.51(\mathrm{~s}, 1 \mathrm{H}), 8.11(\mathrm{~s}, 1 \mathrm{H}), 7.46(\mathrm{~s}, 1 \mathrm{H}), 7.20(\mathrm{~s}, 2 \mathrm{H}), 6.98$ $(\mathrm{d}, J=3.4 \mathrm{~Hz}, 1 \mathrm{H}), 3.69(\mathrm{~s}, 4 \mathrm{H}), 3.49$ (d, $J=5.3 \mathrm{~Hz}, 2 \mathrm{H}), 1.80-$ $1.76(\mathrm{~m}, 2 \mathrm{H}) .{ }^{13} \mathrm{C} \mathrm{NMR}\left(75 \mathrm{MHz}, \mathrm{CDCl}_{3}\right) \delta 168.19,157.44,135.62$, 129.65, 119.11, 117.76, 114.74, 66.47, 57.90, 53.53, 40.05, 24.17.

\section{Synthesis of compound 5}

Compound 3 (26 mg, $0.1 \mathrm{mmol}$ ) was combined with $\mathrm{Et}_{3} \mathrm{~N}$ (420 $\mu \mathrm{L}, 3 \mathrm{mmol}$ ) in $3 \mathrm{~mL}$ dry $\mathrm{CH}_{2} \mathrm{Cl}_{2}$ and the mixture was chill to $0{ }^{\circ} \mathrm{C}$ through an ice bath. Then a portion of compound 4 (0.1 mmol, dissolved in $2 \mathrm{~mL}$ dry $\mathrm{CH}_{2} \mathrm{Cl}_{2}$ ) was added dropwise to the above solution. The resulting reaction mixture was allowed to stir in the ice bath for additional 2 hours. The solvent was removed under reduced pressure and the resultant residue was further purified by silica gel chromatography to give compound 5 as a yellow powder $(27 \mathrm{mg}, 50 \%)$. Mp: $122-125{ }^{\circ} \mathrm{C}$. ${ }^{1} \mathrm{H}$ NMR $\left(300 \mathrm{MHz}, \mathrm{CDCl}_{3}\right) \delta 8.06(\mathrm{~s}, 1 \mathrm{H}), 7.75(\mathrm{~m}, 1 \mathrm{H}), 7.70(\mathrm{~d}, J$ $=9.1 \mathrm{~Hz}, 2 \mathrm{H}), 7.45-7.39(\mathrm{~m}, 2 \mathrm{H}), 6.68(\mathrm{dd}, J=9.3,2.4 \mathrm{~Hz}, 1 \mathrm{H})$, $6.47(\mathrm{~d}, J=2.4 \mathrm{~Hz}, 1 \mathrm{H}), 3.76-3.66(\mathrm{~m}, 4 \mathrm{H}), 3.57$ (d, $J=11.4$, $5.7 \mathrm{~Hz}, 2 \mathrm{H}), 3.46$ (q, $J=7.1 \mathrm{~Hz}, 4 \mathrm{H}), 2.56(\mathrm{dd}, J=12.3,6.0 \mathrm{~Hz}$, $6 \mathrm{H}), 1.87-1.75(\mathrm{~m}, 2 \mathrm{H}), 1.24(\mathrm{t}, J=7.1 \mathrm{~Hz}, 6 \mathrm{H}) \cdot{ }^{13} \mathrm{C}$ NMR $(75$ $\left.\mathrm{MHz} \mathrm{CDCl}_{3}\right) \delta 166.36,161.91,157.65,155.44,152.71,150.62$, 149.36, 136.54, 129.69, 127.90, 124.98, 124.67, 120.31, 111.75, 109.97, 106.17, 96.73, 66.78, 58.34, 53.76, 45.10, 40.35, 24.22, 12.40. HRMS (ESI) $m / z$ : calculated for $\mathrm{C}_{28} \mathrm{H}_{33} \mathrm{ClN}_{3} \mathrm{O}_{6}[\mathrm{M}+\mathrm{H}]^{+}$: 542.2052; found 542.2052.

\section{Synthesis of Lyso-AC}

To a solution of compound 5 (54 mg, $0.1 \mathrm{mmol})$ and $p$-nitrophenol (139 mg, $1 \mathrm{mmol}$ ) in $5 \mathrm{~mL}$ dry $\mathrm{CH}_{3} \mathrm{CN}$ was added $\mathrm{Et}_{3} \mathrm{~N}$ $(140 \mu \mathrm{L}, 1 \mathrm{mmol})$. The mixture was warmed to reflux for 2 hours. After removal of the solvent in vacuo, the resultant residue was further purified by silica gel chromatography to give Lyso-AC as an orange powder (55 mg, 85\%). Mp: $163-166{ }^{\circ} \mathrm{C} .{ }^{1} \mathrm{H}$ NMR (300 $\left.\mathrm{MHz}, \mathrm{CDCl}_{3}\right) \delta 8.25(\mathrm{~d}, J=9.2 \mathrm{~Hz}, 2 \mathrm{H}), 7.91(\mathrm{~s}, 1 \mathrm{H}), 7.63(\mathrm{~d}, J=$ $7.8 \mathrm{~Hz}, 1 \mathrm{H}), 7.42(\mathrm{~s}, 1 \mathrm{H}), 7.35$ (dd, $J=7.8,3.6 \mathrm{~Hz}, 2 \mathrm{H}), 7.19$ (d, $J$ $=9.2 \mathrm{~Hz}, 2 \mathrm{H}), 7.04(\mathrm{dd}, J=8.1,1.5 \mathrm{~Hz}, 1 \mathrm{H}), 6.61-6.52(\mathrm{~m}, 2 \mathrm{H})$, $3.68(\mathrm{~d}, J=6.0 \mathrm{~Hz}, 4 \mathrm{H}), 3.53(\mathrm{dd}, J=11.4,6.0 \mathrm{~Hz}, 2 \mathrm{H}), 3.46$ (q, $J$ $=7.2 \mathrm{~Hz}, 4 \mathrm{H}), 2.56(\mathrm{dd}, J=12.3,6.0 \mathrm{~Hz}, 6 \mathrm{H}), 1.83-1.73(\mathrm{~m}, 2 \mathrm{H})$, $1.24(\mathrm{t}, J=7.1 \mathrm{~Hz}, 6 \mathrm{H}) .{ }^{13} \mathrm{C} \mathrm{NMR}\left(75 \mathrm{MHz}, \mathrm{CDCl}_{3}\right) \delta 166.13$, 164.11 , 161.43, 160.95, 159.39, 157.24, 153.18, 150.40, 143.54, 
136.45, 129.49, 126.20, 124.53, 124.24, 120.24, 116.60, 109.91, 102.76, 102.45, 97.14, 66.84, 58.50, 53.81, 45.18, 40.46, 24.20, 12.39. HRMS (ESI) $m / z$ : calculated for $\mathrm{C}_{34} \mathrm{H}_{36} \mathrm{~N}_{4} \mathrm{NaO}_{9}[\mathrm{M}+\mathrm{Na}]^{+}$: 667.2374; found 667.2375.

\section{Results and discussion}

\section{Design and synthesize}

Motivated by the above-mentioned concerns, we invested effort into exploiting a lysosome-targetable fluorescent probe that could simultaneously sense Cys/Hcy and GSH from distinct emissions. As shown in Scheme 1, the probe, Lyso-AC, was designed based on the following concerns: (1) 7-diethylaminocoumarin was selected as the fluorophore due to its outstanding optical properties. ${ }^{33}$ Moreover, the photophysical properties of 7-diethylaminocoumarin is adjustable, which can be easily tuned through proper structure modification. For instance, in 2013 Guo's group reported several amino- and thiol-modified diethylaminocoumarin dyes, and the absorption of 4-amino-7-diethylaminocoumarin peaks at about $360 \mathrm{~nm}$ whereas the 4-thio-7-diethylaminocoumarin absorbs at about $385 \mathrm{~nm} .{ }^{19}$ We speculated that coupling the remarkable photophysical differences of amino- and thiodiethylaminocoumarin with the unique Cys/Hcy-triggered substitution-rearrangement cascade would serve as an effective approach to sense Cys/Hcy and GSH simultaneously. (2) 4Nitrophenol moiety was chosen as the biothiols recognition group. First, it can function as an effective leaving group. Second, it also can act as a quencher to minimize the background fluorescence signal of the probe via the efficient d-PET process. Furthermore, the 4-nitrophenol moiety should be linked to the 4 position of the coumarin, so that it can be activated by two nearby carbonyls. ${ }^{34}$ (3) A morpholine moiety was employed as the lysosome targeting group due to the effective lysosome-targetable feature of this moiety. ${ }^{35-42}$

Finally, by considering all above issues, Lyso-AC was designed by integrating a 4-nitrophenol moiety and a morpholine moiety into a diethylaminocoumarin dye (Scheme 1). We speculated that the addition of Cys (or Hcy) to Lyso-AC would initially result the corresponding $\mathrm{S}_{\mathrm{N}} \mathrm{Ar}$ substituted product LysoAC-S-Cys (or Lyso-AC-S-Hcy) and the subsequent Smiles rearrangement would ultimately generate the Lyso-AC-N-Cys (or Lyso-AC-N-Hcy) via a five (or six)-membered cyclic intermediate.

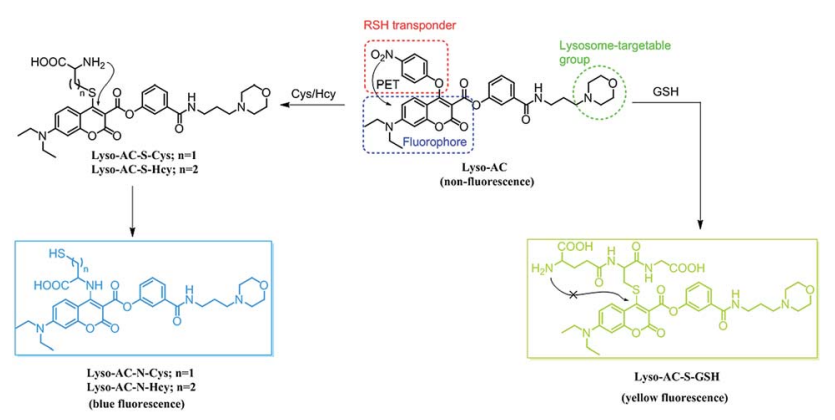

Scheme 1 Proposed sensing mechanism of Lyso-AC for Cys/Hcy and GSH.
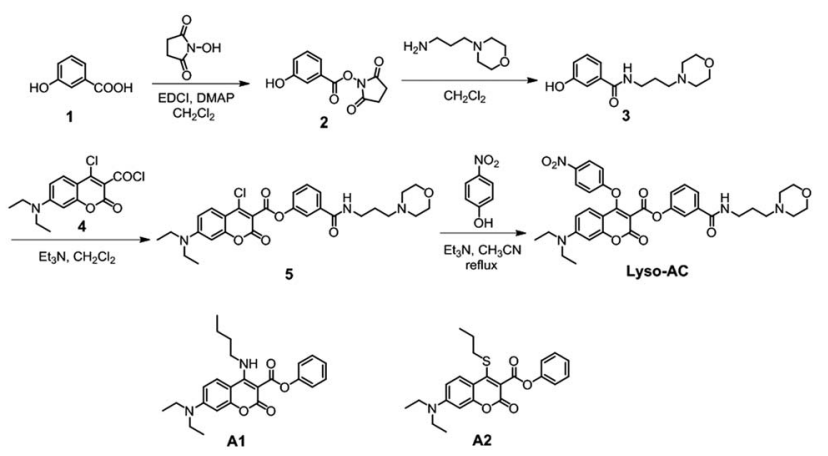

Scheme 2 Synthetic route for Lyso-AC and the chemical structures of reference dyes $\mathrm{A} 1$ and $\mathrm{A} 2$.

In the case of GSH, Lyso-AC-S-GSH is expected to generate. However the following intermolecular Smiles rearrangement of Lyso-AC-S-GSH is difficult to undergo due to the fact that an unstable transition state would be involved in during this process. Based on the distinct emission wavelengths of the 4amino- and 4-thio-diethylaminocoumarin, simultaneous detection of lysosomal Cys/Hcy and GSH from distinct emission signals would likely to be realized.

As a proof of concept, Lyso-AC was synthesized through the corresponding synthetic route in Scheme 2 (details were shown in the Experimental section). The structure of Lyso-AC was fully identified by HRMS spectrum and NMR spectra (see in $\mathrm{ESI} \dagger$ ).

\section{UV-vis spectra studies}

First, the reactivity of Lyso-AC toward Cys/Hcy/GSH was examined through time-dependent UV-vis spectra in PBS buffer (10 mM, pH 7.4, containing 20\% DMSO). Free Lyso-AC exhibited a major absorption band centred at $430 \mathrm{~nm}\left(\varepsilon=4.34 \times 10^{4} \mathrm{~L}\right.$ $\mathrm{mol}^{-1} \mathrm{~cm}^{-1}$ ). As expected, upon treatment of 10 equivalents of Cys to Lyso-AC, the initial peak at $430 \mathrm{~nm}$ decreased gradually, along with simultaneous occurrence of a new absorption peak at $383 \mathrm{~nm}$ (Fig. 1A and B). The absorption peak at $383 \mathrm{~nm}$ belongs to Lyso-AC-N-Cys, which was further demonstrated by the reference dye $\mathbf{A 1}$, whose absorption peak was determined to be around $383 \mathrm{~nm}$ (Fig. S1†). Similar results can be observed when addition of 10 equivalents of Hcy to Lyso-AC (Fig. 1C, D and Fig. $\mathrm{S} 2 \dagger$ ). By contrast, upon treatment 10 equivalents of GSH to Lyso-AC, the absorption peak at $430 \mathrm{~nm}$ decreased and slightly blue-shifted to $426 \mathrm{~nm}$. Unlike the case of Cys or Hcy, no absorption peak at $383 \mathrm{~nm}$ in this case can be seen, indicating the failure of the subsequent intramolecular rearrangement in this case (Fig. 1E and F). The new slightly blue-shifted peak at $423 \mathrm{~nm}$ belongs to Lyso-AC-S-GSH, which was further supported by the reference dye $\mathbf{A 2}$ (Fig. S3 $\dagger$ ). In addition, all adducts (LysoAC-N-Cys, Lyso-AC-N-Hcy and Lyso-AC-S-GSH) were detectable in the corresponding HRMS data (Fig. S4-S6†). All to all, the above traits in good agreement with the mechanism proposed in Scheme 2. Moreover, the photostability of Lyso-AC has been studied. As show in Fig. S7, $\uparrow$ it appears a favourable photostability of Lyso-AC. 

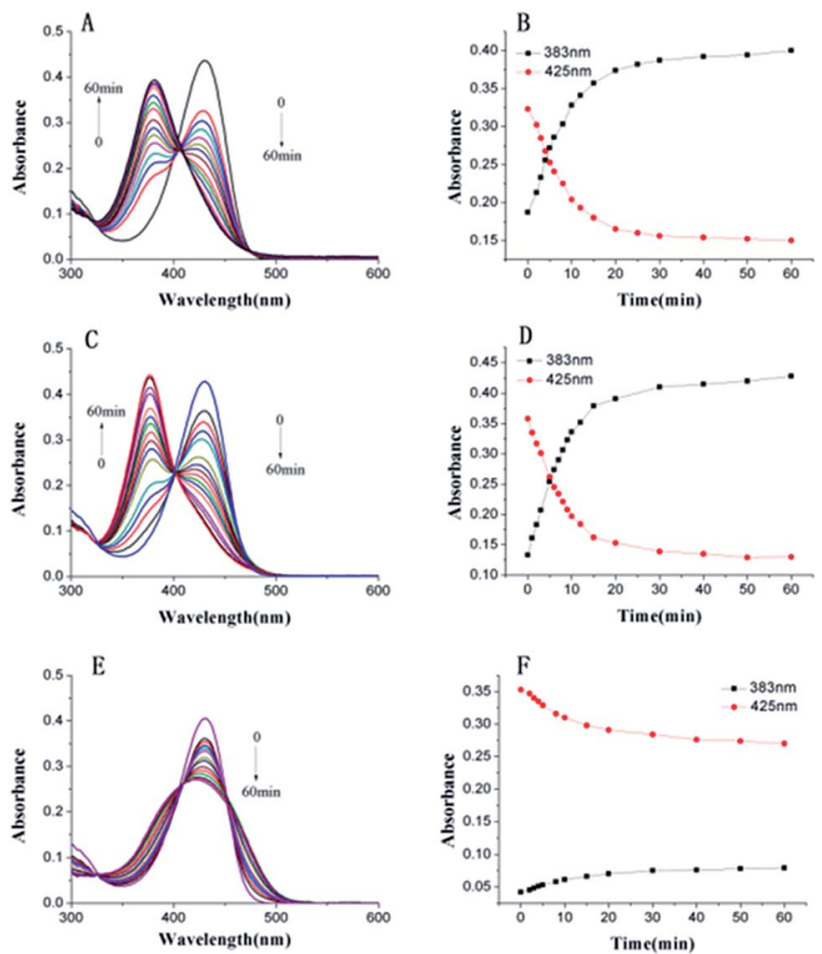

Fig. 1 Time-dependent absorption spectra of Lyso-AC $(10 \mu \mathrm{M})$ in the presence of 10 equiv. of Cys (A), Hcy (C) or GSH (E) in PBS buffer ( $\mathrm{pH}$ 7.4, $10 \mathrm{mM}$, containing 20\% DMSO, v/v) at room temperature. Timedependent absorption intensity changes toward 10 equiv. of Cys (B), Hcy (D) or GSH (F) at $425 \mathrm{~nm}$ and $383 \mathrm{~nm}$ in PBS buffer (pH 7.4, $10 \mathrm{mM}$, containing $20 \% \mathrm{DMSO}, \mathrm{v} / \mathrm{v}$ ) at room temperature.

\section{Fluorescence spectra studies}

The emission behaviours of Lyso-AC upon addition of Cys, Hcy and GSH were further evaluated. Initially, time-dependent fluorescence spectra of Lyso-AC with respective biothiols were studied. The corresponding fluorescence spectra were first measured with an excitation wavelength of $383 \mathrm{~nm}$. Free LysoAC was essentially non-fluorescence due to the efficient d-PET process. However, upon treatment of 10 equivalents of Cys to Lyso-AC, a remarkable fluorescence enhancement (19.5-fold) at $485 \mathrm{~nm}$ can be observed due to the production of Lyso-AC-N-Cys (Fig. 2A1). A similar observation was made in the case of Hcy (about 16.5-fold enhancement at $485 \mathrm{~nm}$ ) (Fig. 2A2). However, in comparison with Cys/Hcy, GSH elicited only a slight fluorescence enhancement (3.6-fold) at $485 \mathrm{~nm}$ (Fig. 2A3). These results demonstrated that Lyso-AC can be used to discriminate Cys/Hcy from GSH when excited at $383 \mathrm{~nm}$. Moreover, the kinetic studies revealed that Lyso-AC respond to Cys/Hcy obey classic pseudo-first-order reaction, and the corresponding rate constants $\mathrm{k}_{\mathrm{obs}}$ determined to be about $0.0727 \mathrm{~min}^{-1}$ for Cys (Fig. S8 $\dagger$ ) and $0.0931 \mathrm{~min}^{-1}$ for Hcy (Fig. S9†).

Next, the fluorescence response of Lyso-AC toward Cys/Hcy/ GSH was further investigated by using excitation at $425 \mathrm{~nm}$. Similarly, Lyso-AC displayed weak fluorescence under this excitation wavelength. Upon introduction of 10 equivalents of GSH to Lyso-AC, fluorescence at $550 \mathrm{~nm}$ increased rapidly and then got saturation within $60 \mathrm{~min}$ (Fig. 2B3). On the other hand,
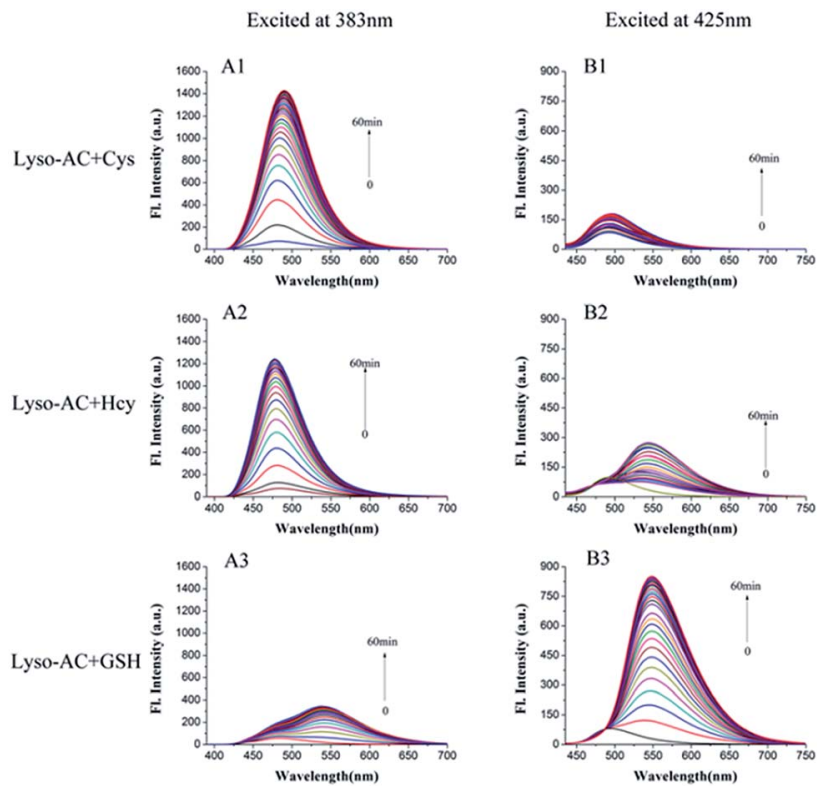

Fig. 2 Time-dependent fluorescence response of Lyso-AC (10 $\mu \mathrm{M})$ toward 10 equiv. of Cys, Hcy and GSH excited at $383 \mathrm{~nm}$ (A1-A3). Time-dependent fluorescence intensity changes toward 10 equiv. of Cys, Hcy and GSH excited at $425 \mathrm{~nm}$ (B1-B3). Condition: slits, 5/5 nm; PBS buffer (10 mM, pH 7.4, containing $20 \%$ DMSO) at $25^{\circ} \mathrm{C}$.

introduction of 10 equivalents of Cys or Hcy did not elicit remarkable fluorescence at $550 \mathrm{~nm}$ (Fig. 2B1 and B2). The corresponding fluorescence increments at $550 \mathrm{~nm}$ for GSH, Cys and Hcy were 29.7-, 2.7- and 2.4-fold respectively. These results indicated that Lyso-AC was capable of differentiate GSH from Cys/Hcy when excited at $425 \mathrm{~nm}$. Notably, the reaction between Lyso-AC and GSH also obeys a classic pseudo-first-order and the corresponding $K_{\text {obs }}$ was determined to be $0.0506 \mathrm{~min}^{-1}$ (Fig. S10†).

To evaluate the sensitivity of Lyso-AC, fluorescence titration experiments were conducted. Upon addition of increasing amounts of Cys (or Hcy), the fluorescence intensity of Lyso-AC at $485 \mathrm{~nm}$ increased gradually. Moreover, as shown in Fig. S11 and $\mathrm{S} 12, \uparrow$ a good linearity between fluorescence intensity at $485 \mathrm{~nm}$ and concentrations of Cys $(0-60 \mu \mathrm{M})$ or Hcy $(0-45 \mu \mathrm{M})$ was observed. The detection limits for Cys and Hcy were calculated to be $0.86 \mu \mathrm{M}$ and $1.52 \mu \mathrm{M}$, respectively. As for GSH, the fluorescence at $550 \mathrm{~nm}$ increases with the incremental GSH added and a good linearity between $F_{550}$ and concentrations of GSH in the range of $0-40 \mu \mathrm{M}$ was observed (Fig. S13 $\dagger$ ). And the corresponding detection limit was determined to be $1.75 \mu \mathrm{M}$.

\section{Selectivity studies and $\mathrm{pH}$ effect}

To examine the selectivity of Lyso-AC toward Cys/Hcy and GSH, the fluorescence behaviour of Lyso-AC in response to various biologically related species, including some essential amino acids (Tyr, Val, Gly, Ala, Asp, Arg, Iso, Lys, Met, His, Phe, Thr, Ser, Pro and Glu, $0.5 \mathrm{mM}$ for each), biological metal ions $\left(\mathrm{Ca}^{2+}\right.$, $\mathrm{Na}^{+}, \mathrm{K}^{+}, \mathrm{Zn}^{2+}$ and, $\mathrm{Mg}^{2+} 0.5 \mathrm{mM}$ for each), hydrogen sulphide $\left(\mathrm{H}_{2} \mathrm{~S}, 0.5 \mathrm{mM}\right)$ as well as reactive oxygen species $\left(\mathrm{H}_{2} \mathrm{O}_{2}, 0.1 \mathrm{mM}\right)$ 

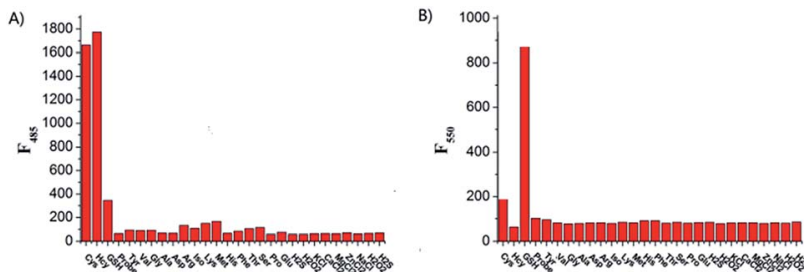

Fig. 3 Fluorescence intensity of Lyso-AC $(10 \mu \mathrm{M})$ at $485 \mathrm{~nm}(\mathrm{~A})$ and $550 \mathrm{~nm}$ (B) upon addition of various species in PBS buffer $(\mathrm{pH} 7.4$, $10 \mathrm{mM}$, containing $20 \% \mathrm{DMSO}$ ) at $25^{\circ} \mathrm{C}$. Each spectrum recorded at 60 min after addition of the corresponding species.

were investigated, The fluorescence intensities were then measured at $485 \mathrm{~nm}$ and $550 \mathrm{~nm}$, respectively. As illustrated in Fig. 3A, only Cys/Hcy induced a significant fluorescence enhancement at $485 \mathrm{~nm}$ whereas other analytes, including the GSH and $\mathrm{H}_{2} \mathrm{~S}$, gave marginal increments. On the other hand, with the excitation of $425 \mathrm{~nm}$, all these interfering species caused insignificant fluorescence variations, and only GSH caused noticeable fluorescence enhancement at $550 \mathrm{~nm}$ (Fig. 3B). These results suggesting Lyso-AC is highly selective for Cys/Hcy or GSH. In addition, the effect of $\mathrm{pH}$ values were also examined, and the results indicating Lyso-AC was quite stable over a wide $\mathrm{pH}$ range (1-10), and displayed noticeable fluorescence enhancements upon treatment of Cys, Hcy or GSH in the region of 4-10 (Fig. S14 $\dagger$ ). Therefore, Lyso-AC is suitable to be used at physiological $\mathrm{pH}$ range.

\section{Cell imaging}

On the basis of the above excellent sensing traits of Lyso-AC, we sought to further investigate the capability of Lyso-AC to selectively detect intracellular Cys/Hcy and GSH at the same time. When HeLa cells were treated with $2 \mu \mathrm{M}$ Lyso-AC, a strong fluorescence in yellow channel was observed, implying the reaction of intracellular GSH with the probe (Fig. 4A2). When HeLa cells were successive treated with $1 \mathrm{mM}$ NEM and $1 \mathrm{mM}$ Cys (or Hcy), then further treated with $2 \mu \mathrm{M}$ Lyso-AC, a strong fluorescence in blue channel (Fig. 4B1 or Fig. 4C1) and an insignificant fluorescence in yellow channel (Fig. 4B2 or Fig. 4C2) were taking place. When HeLa cells were successive treated with $1 \mathrm{mM}$ NEM and $1 \mathrm{mM} \mathrm{GSH}$, then further treated with $2 \mu \mathrm{M}$ Lyso-AC, an obvious fluorescence in yellow channel (Fig. 4D2) and negligible emission in blue channel (Fig. 4D1) were observed. For comparison, HeLa cells were successively introduced with $1 \mathrm{mM}$ NEM and $2 \mu \mathrm{M}$ Lyso-AC. As a result, negligible emissions can be observed both in blue channel and yellow channel (Fig. 4E1-E4). Moreover, to verify Lyso-AC is lysosome targetable, colocalization experiments were performed by using Lyso-AC and a commercial lysosome sensor Neutral Red (NR) (Fig. 5). As shown in Fig. 5C, the fine merged images strongly convinced that Lyso-AC fits well with lysosomes inside the cells with a Pearson's coefficient of 0.92. These experiments demonstrated that Lyso-AC can specifically localize in lysosomes and be used to detect Cys/Hcy and GSH in lysosomes of living HeLa cells. In addition, Lyso-AC exhibited

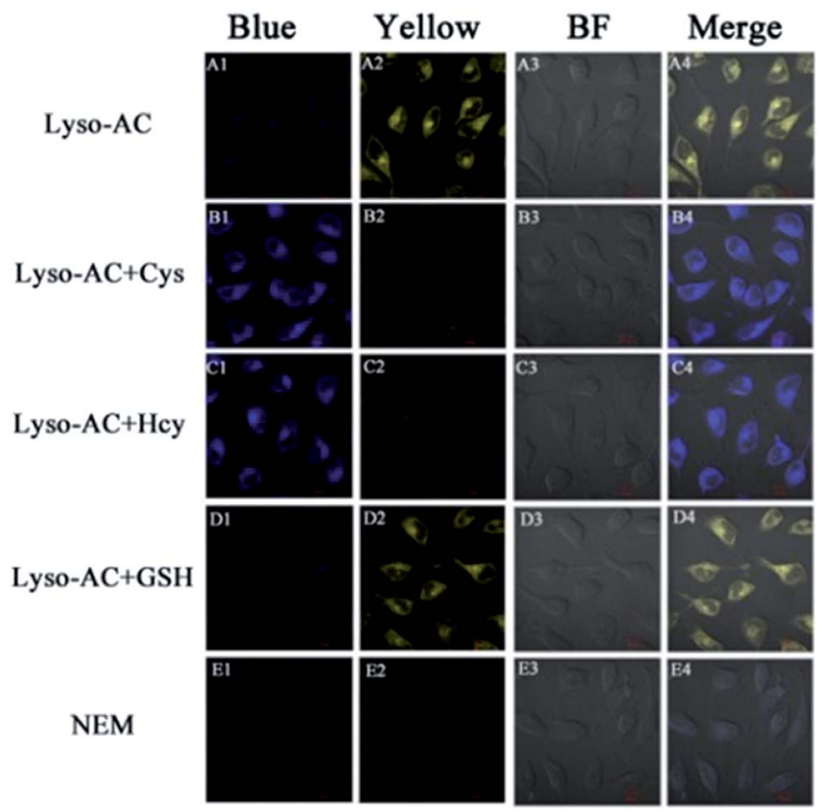

Fig. 4 Confocal microscopic images of biothiols in living HeLa cells. (A1-A4) HeLa cells pretreated with incubated with $2 \mu \mathrm{M}$ Lyso-AC for $30 \mathrm{~min}$; HeLa cells pretreated with $1 \mathrm{mM}$ NEM for $15 \mathrm{~min}$ then $1 \mathrm{mM}$ Cys (B1-B4), Hcy (C1-C4), or GSH (D1-D4) for $15 \mathrm{~min}$, finally incubated with $2 \mu \mathrm{M}$ Lyso-AC for additional 30 min; (E1-E4) HeLa cells pretreated with $1 \mathrm{mM} \mathrm{NEM}$ for $15 \mathrm{~min}$ and then incubated with $2 \mu \mathrm{M}$ Lyso-AC for $30 \mathrm{~min}$. Excitation wavelength; $405 \mathrm{~nm}$. Emissions were collected at 450-490 $\mathrm{nm}$ for blue channel and 540-580 nm for yellow channel. Scale bar: $10 \mu \mathrm{m}$.
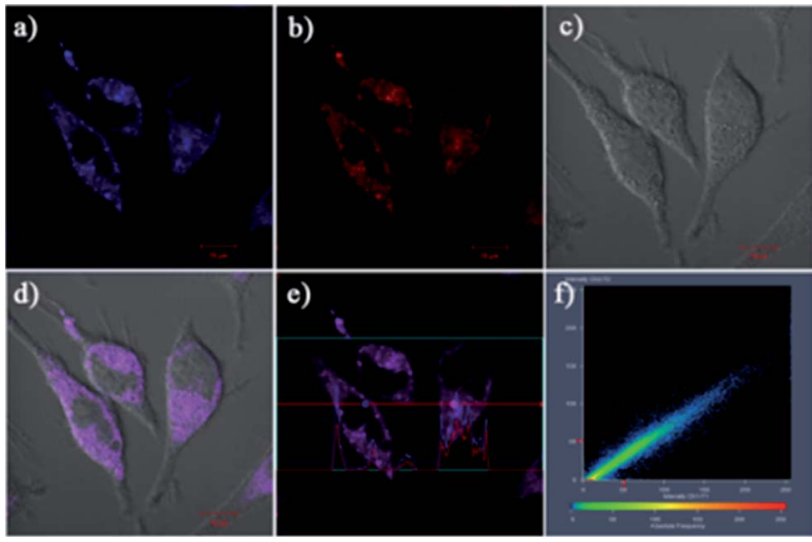

Fig. 5 The images of living HeLa cells co-stained with Lyso-AC $(2 \mu \mathrm{M})$ and Lyso-Tracker NR $(2 \mu \mathrm{M})$ for $30 \mathrm{~min}(\mathrm{a}-\mathrm{c})$. (a) Blue channel $\left(\lambda_{\mathrm{ex}}=\right.$ $\left.405 \mathrm{~nm}, \lambda_{\mathrm{em}}=450-490 \mathrm{~nm}\right)$; (b) red channel image $\left(\lambda_{\mathrm{ex}}=559 \mathrm{~nm}, \lambda_{\mathrm{em}}\right.$ $=586-610 \mathrm{~nm})$; (c) bright field; (d) merged images of $(\mathrm{a}-\mathrm{c})$; (e) intensity profile of regions of interest across HeLa cells; (f) Intensity correlation plot of Lyso-AC and NR. Scale bar: $10 \mu \mathrm{m}$.

minimal cytotoxicity, which was supported by corresponding MTT assay (Fig. S15†).

\section{Conclusions}

In conclusion, we have developed a novel lysosome targetable fluorescent probe, Lyso-AC, which can selectively detect 
lysosomal Cys/Hcy and GSH from distinct emission signals. Preliminary cell imaging studies have revealed that Lyso-AC was capable of sensing Cys/Hcy and GSH in living HeLa cells at the same time. We hope this probe can become a robust tool for lysosomal biothiols investigation.

\section{Conflicts of interest}

There are no conflicts to declare.

\section{Acknowledgements}

This work was supported by the Guangxi Natural Science Foundation (2016GXNSFBA380229, 2017GXNSFA198342), Guangxi Scientific and Technological Development Projects (AD17195081), "BAGUI Scholar" program of Guangxi Province of China, and the Fundamental Research Funds for the Central Universities of Central South University (2018zzts109).

\section{Notes and references}

1 N. Brandes, S. Schmitt and U. Jakob, Antioxid. Redox Signaling, 2009, 11, 997-1014.

2 D. M. Townsend, K. D. Tew and H. Tapiero, Biomed. Pharmacother., 2003, 57, 145-155.

3 M. T. Heafield, S. Fearn, G. B. Steventon, R. H. Waring, A. C. Williams and S. G. Sturman, Neurosci. Lett., 1990, 110, 216-220.

4 P. Sachdev, J. Neurol. Sci., 2004, 226, 81-87.

5 Z. A. Wood, E. Schroder, J. H. Robin and L. B. Poole, Trends Biochem. Sci., 2003, 28, 32-40.

6 L. Yuan, W. Lin, K. Zheng, L. He and W. Huang, Chem. Soc. Rev., 2013, 42, 622-661.

7 M. Fernandez-Suarez and A. Y. Ting, Nat. Rev. Mol. Cell Biol., 2008, 9, 929-943.

8 J. Chan, S. C. Dodani and C. J. Chang, Nat. Chem., 2012, 4, 973-977.

9 X. Chen, Y. Zhou, X. Peng and J. Yoon, Chem. Soc. Rev., 2010, 39, 2120-2135.

10 Y. Zhou and J. Yoon, Chem. Soc. Rev., 2011, 41, 52-67.

11 L. Y. Niu, Y. Z. Chen, H. R. Zheng, L. Z. Wu, C. H. T and Q. Z. Yang, Chem. Soc. Rev., 2015, 44, 6143-6160.

12 Y. M. Yang, Q. Zhao, W. Feng and F. Y. Li, Chem. Rev., 2013, 113, 192-270.

13 Y. Li, W. M. Liu, P. P. Zhang, H. Y. Zhang, J. S. Wu, J. C. Ge and P. F. Wang, Biosens. Bioelectron., 2017, 90, 117-124.

14 X. F. Yang, W. Y. Liu, J. Tang, P. Li, H. B. Weng, Y. Ye, M. Xian, B. Tang and Y. F. Zhao, Chem. Commun., 2018, 54, 11387-11390.

15 D. Qiao, T. L. Shen, M. Y. Zhu, X. Liang, L. Zhang, Z. Yin, B. H. Wang and L. Q. Shang, Chem. Commun., 2018, 54, 13252-13255.

16 C. Y. Zhang, S. Wu, Z. Xi and L. Yi, Tetrahedron, 2017, 73, 6651-6656.

17 L. Sun, Y. Q. Jiang, C. Y. Zhang, X. R. Ji, D. Q. Lv, Z. Xi and L. Yi, New J. Chem., 2018, 42, 15277-15283.
18 C. X. Yin, K. M. Xiong, F. J. Huo, J. C. Salamanca and R. M. Strongin, Angew. Chem., Int. Ed., 2017, 56, 1318813198.

19 J. Liu, Y. Q. Sun, Y. Huo, H. Zhang, L. Wang, P. Zhang, D. Song, Y. Shi and W. Guo, J. Am. Chem. Soc., 2014, 136, 574-577.

20 H. Kimura, Amino Acids, 2011, 41, 113-121.

21 O. Rusin, N. N. S. Luce, R. A. Agbaria, J. O. Escobedo, S. Jiang, I. M. Warner, F. B. Dawan, K. Lian and R. M. Strongin, J. Am. Chem. Soc., 2004, 126, 438-439.

22 J. Liu, Y. Q. Sun, Y. Huo, H. Zhang, L. Wang, P. Zhang, D. Song, Y. Shi and W. Guo, J. Am. Chem. Soc., 2014, 136, 574-577.

23 X. F. Yang, Q. Huang, Y. G. Zhong, Z. Li, H. Li, M. Lowry, J. O. Escobedo and R. M. Strongin, Chem. Sci., 2014, 5, 2177-2183.

24 J. Liu, Y. Q. Sun, H. X. Zhang, Y. Y. Huo, Y. W. Shi and W. Guo, Chem. Sci., 2014, 5, 3183-3188.

25 F. Y. Wang, L. Zhou, C. C. Zhao, R. Wang, Q. Fei, S. H. Luo, Z. Q. Guo, H. Tian and W. H. Zhu, Chem. Sci., 2015, 6, 25842589.

26 W. Q. Chen, H. C. Luo, X. J. Liu, W. F. James and X. Z. Song, Anal. Chem., 2016, 88, 3638-3646.

27 G. X. Yin, T. T. Niu, Y. B. Gan, T. Yu, P. Yin, H. M. Chen, Y. Y. Zhang, H. T. Li and S. Z. Yao, Angew. Chem., Int. Ed., 2018, 57, 4991-4994.

28 K. Surendran, S. P. Vitiello and D. A. Pearce, Pediatr. Nephrol., 2014, 29, 2253-2261.

29 S. Carmine, F. Alessandro, D. L. Medina and B. Andrea, Nat. Rev. Mol. Cell Biol., 2013, 14, 283-296.

30 D. R. Balce, E. R. O. Allan, N. McKenna and R. M. Yates, J. Biol. Chem., 2014, 289, 31891-31904.

31 Q. K. Gao, W. Z. Zhang, B. Song, R. Zhang, W. H. Guo and J. L. Yuan, Anal. Chem., 2017, 89, 4517-4524.

32 J. L. Mego, J. Biol. Chem., 1984, 218, 775-783.

33 S. Sanghi, D. Mohan and R. D. Singh, Asian J. Phys., 1995, 4, 283-288.

34 Y. Kim, S. V. Mulay, M. Choi, S. B. Yu, S. Jon and D. G. Churchill, Chem. Sci., 2015, 6, 5435-5439.

35 M. G. Ren, Z. H. Li, J. Nie, L. Wang and W. Y. Lin, Chem. Commun., 2018, 54, 9238-9241.

36 Y. Liu, F. F. Meng, L. W. He, K. Y. Liu and W. Y. Lin, Chem. Commun., 2016, 52, 7016-7019.

37 B. L Dong, X. Z. Song, C. Wang, X. Q. Kong, Y. H. Tang and W. Y. Lin, Anal. Chem., 2016, 88, 4085-4091.

38 M. G. Ren, B. B. Deng, J. Y. Wang, X. Q. Kong, Z. R. Liu, K. Zhou, L. W. He and W. Y. Lin, Biosens. Bioelectron., 2016, 79, 237-243.

39 H. B. Yu, Y. Xiao and L. J. Jin, J. Am. Chem. Soc., 2012, 134, 17486-17489.

40 X. T. Jing, F. B. Yu and L. X. Chen, Chem. Commun., 2014, 50, 14253-14256.

41 T. Y. Liu, Z. C. Xu, D. R. Spring and J. N. Cui, Org. Lett., 2013, 15, 2310-2313.

42 M. G. Ren, B. B. Deng, J. Y. Wang, X. Q. Kong, Z. R. Liu, K. Zhou, L. W. He and W. Y. Lin, Biosens. Bioelectron., 2016, 79, 237-243. 